\title{
CFD ANALYSIS OF HUMAN POWERED SUBMARINE TO MINIMIZE DRAG
}

\author{
SHER AFGHAN KHAN ${ }^{1}$, M. A. FATEPURWALA ${ }^{2}$, K. N. PATHAN ${ }^{3}$, \\ P. S. DABEER ${ }^{4} \&$ MAUGHAL AHMED ALI BAIG ${ }^{5}$ \\ ${ }^{1}$ Department of Mechanical Engineering, Faculty of Engineering, IIUM, Malaysia \\ ${ }^{2,3,4}$ Trinity College of Engineering and Research, Pune, Maharashtra, India \\ ${ }^{5}$ Department of Mechanical Engineering, CMR Technical Campus, Hyderabad, Telangana, India
}

\begin{abstract}
This paper deals with finding the optimum fineness ratio, i.e. ratio of length to maximum diameter, of human -powered submarine of different shapes to reduce the drag force on the body using Computational Fluid Dynamics (CFD) analysis. These types of submarines are used in events like ISR and eISR. This paper focuses on finding the total drag force on submarine models with a constrained diameter and different fineness ratios. The analysis is done by using ANSYS Fluent. In this paper, only the fully submerged flow is considered on a hull without any appendages. The total drag on a body is caused in three different parts that are wave drag, skin friction drags and base drag. The analysis is done different shapes of submarines like Conic shape hull, Elliptical shape hull, Ogive shape hull and Parallel mid-body hull by flowing water at velocities of $3 \mathrm{~m} / \mathrm{s}, 4 \mathrm{~m} / \mathrm{s}$ and $5 \mathrm{~m} / \mathrm{s}$. The fineness ratios at which the drag is minimum are found in all submarine shapes. The optimum value of fineness ratio, which gives minimum drag is obtained by the analysis is 6 for Conical shape hull, Elliptical shape hull and Ogive shape hull whereas for the submarine with Parallel mid-body hull shape the optimum fineness ratio is 7
\end{abstract}

KEYWORDS: CFD, Drag, Fineness Ratio \& Submarine

Received: Apr 12, 2018; Accepted: May 25, 2018; Published: Jun 18, 2018; Paper Id.: IJMPERDJUN2018111

\section{INTRODUCTION}

Mostly submarines find their use in the defense sector as attack submarines, aircraft carrier protection and also as a nuclear strike force to launch ballistic missiles. Apart from this submarine recently are also being used for recreational purposes and as a sport. These submarines are usually one manned human-powered submarines. Competitions like the International Submarine Races (ISR) and the European International Submarine Races (eISR) have promoted the development of human-powered submarines at a university level $[1,2]$. These Human-powered submarines can also be used in fields like marine biology and oceanography to carry out research on various underwater creatures and plants. Researchers can get easy access to the marine world using these submarines as they require no fuel and are easy to operate. These submarines are also eco-friendly as they are completely human powered and cause no damage to the environment. The design of the shape of the submarine mainly depends on the hydrodynamics of the submarine-like other marine vehicles such as ships and underwater missiles. In human-powered submarines as there is no other source of energy available it is very important to minimize the resistance on these submarines. These submarines can navigate in two different modes which are: on the surface of the water and incompletely submerged mode. As maximum drag occurs in completely submerged mode of 
navigation the design is considered only completely submerged body. Other factors that must be taken into consideration by the submarine design are human comfort and overall weight of the submarine. The submarine should have dimensions to accommodate a person and also the necessary equipment. If the weight of the submarine is too much the effort required to power the submarine will also increase. It should also have enough space for components like the drive-train, pedals, steering handle and the oxygen tank. As these submarines are used for races and are human powered, having minimum drag is very important in the hydrodynamic design of these submarines. Generally, submarines have two major categories of hydrodynamic shape which are tear drop or ogive shape and parallel mid-body shape. The parallel mid-body shape is usually used in naval submarines, but as the size of the one manned submarine is very less the tear drop or ogive shape is preferred as it offers less drag.

The bare hull design is done by using the bow form equations called hull envelope equations. The total length of the hull is divided into four e-body $\left(\mathrm{L}_{\mathrm{f}}\right)$ and the after-body $\left(\mathrm{L}_{\mathrm{a}}\right)$ as shown in Figure1.

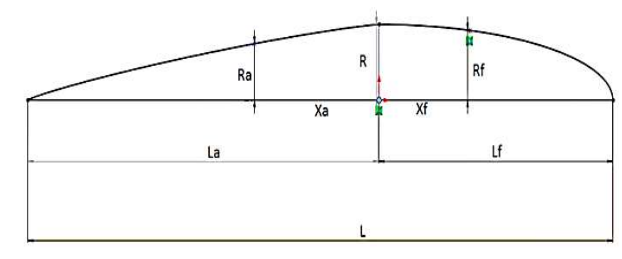

Figure 1: Bow Form

The curve of the fore body is elliptical and that of the after body is conical. The length of the fore body is $40 \%$ of the total length and the after body is $60 \%$ of the total length. The equation of the curve of the fore body is given as

$$
\mathrm{R}_{\mathrm{f}}=\mathrm{R}\left[1-\left(\mathrm{X}_{\mathrm{f}} / \mathrm{L}_{\mathrm{f}}\right)^{\mathrm{n}}\right]^{1 / \mathrm{n}}(1)
$$

The equation of the curve of the after body is given as

$$
\mathrm{R}_{\mathrm{a}}=\mathrm{R}\left[1-\left(\mathrm{X}_{\mathrm{a}} / \mathrm{L}_{\mathrm{a}}\right)^{\mathrm{n}}\right]^{1 / \mathrm{n}}(2)
$$

The ratio of the total length of the maximum diameter of the body is called as the fineness ratio (L/D). The fineness ratio of a body has a direct impact on the total drag acting on the body. In this paper submarine model with a different fineness ratio are tested using Computational Fluid Dynamics (CFD). The diameter of the submarine is kept constant at $609.6 \mathrm{~mm}$ (24 inches) which is the required diameter to accommodate one person and the total length is varied to obtain different fineness ratios. The dimensions of the submarine at different fineness ratios are given in table 1 . The fineness ratios from 4 to 8 are taken as this is the feasible range considering the height of an average person. [3, 4]

Table 1: Dimensions of Submarine at Different Fineness Ratios

\begin{tabular}{|c|c|c|c|}
\hline $\begin{array}{c}\text { Fineness } \\
\text { Ratio(L/D) }\end{array}$ & $\begin{array}{c}\text { Total Length } \\
(\mathbf{L}) \text { inch }\end{array}$ & $\begin{array}{c}\text { Fore Body Length } \\
\left(\mathbf{L}_{\mathbf{f}}\right) \text { inch }\end{array}$ & $\begin{array}{c}\text { After Body Length } \\
\left(\mathbf{L}_{\mathbf{a}}\right) \text { inch }\end{array}$ \\
\hline 4 & 2438.4 & 975.36 & 1463.04 \\
\hline 5 & 3048 & 1219.2 & 1828.8 \\
\hline 6 & 3657.6 & 1463.04 & 2194.56 \\
\hline 7 & 4267.2 & 1706.88 & 2560.32 \\
\hline 8 & 4876.8 & 1950.72 & 2926.08 \\
\hline
\end{tabular}

The drag force generated is analyzed for different fineness ratios at different speeds using CFD. This will provide us 
with the correlation between the fineness ratio and the total drag generated and will help in determining the optimum fineness ratio required to design a human powered submarine.

\section{CFD ANALYSIS}

Pathan et al., analyzed the drag force for different fineness ratios the models were first created using Ansys Workbench and the curves for the fore and after body were created using equation driven curve tool. The geometry was then revolved to form the shape of the bare hull [5,6,7]. In this paper, four different types of submarines shapes are compared to determine the most optimum hydrodynamic shape as well as the best fineness ratio of each of these shapes. The dimensions for all the models are kept constant as given in Table.1. The only changes made to the model are the shape of the curves of the fore and after body. These changes in the shape are done by changing the value of the parameter ' $n$ ' in the equation of the curves (1) and (2). Increasing the value of ' $n$ ' also increases the degree of the curve. Keeping the value of ' $n$ ' in between 1 to 1.5 gives a cone type of curve, whereas if the value is kept at 2 it results in an elliptical curve. The shapes of different curves for different values of ' $n$ ' are given in the figures below.

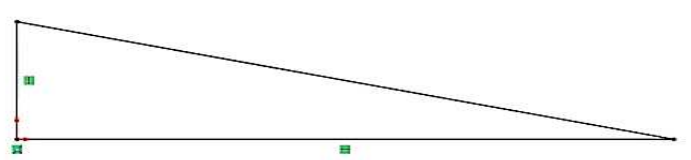

(A) $\mathbf{n}=\mathbf{1}$

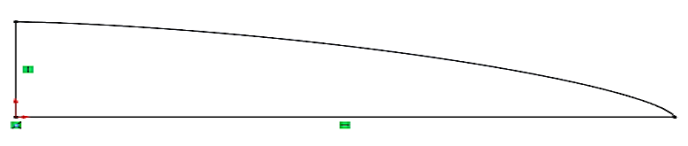

(C) $\mathbf{n}=\mathbf{1 . 5}$

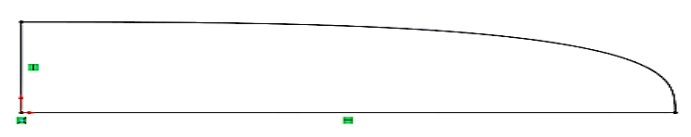

(E) $n=3$

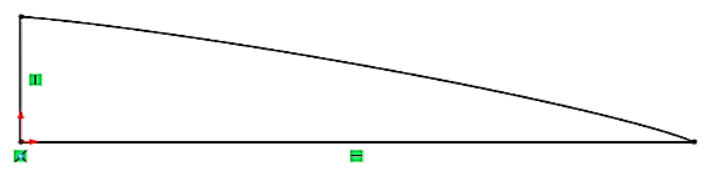

(B) $\mathrm{n}=\mathbf{1 . 2}$

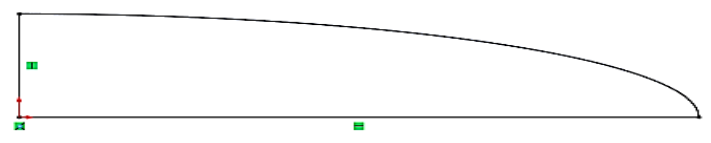

(D) $n=2$

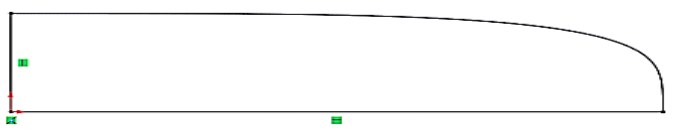

(F) $n=4$

Figure 2: Variation of Shape with 'n'

\section{Conic Shape Bow}

In this model the fore and after body curves are taken as conic curves. The value of ' $\mathrm{n}$ ' for the governing equation of the curve is taken as 1.2. In this model the body is very streamlined with sharp edges. It also has a very small volume as compared to the other models. The figure below shows the conic shape model.

\section{Elliptical Shape Bow}

In this model both the fore and after body curves are ellipses. The value of ' $n$ ' for both the curves is taken as 2 . This model is less streamlined than the conic shape model, but has a greater volume. The curves in this model are smoother than that of the conic which would make the flow around the hull more streamlined. The increase in the degree of the curve also increases the surface area of the hull. The figure below shows the shape of the elliptical hull. 


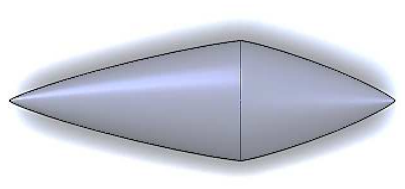

Figure 3: Conic Shape

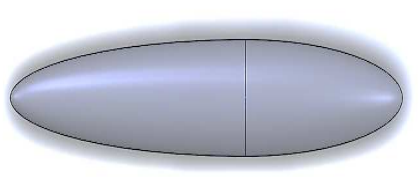

Figure 4: Elliptical Shape Bow

\section{O give or Tear Drop Shape Bow}

In this model the value of ' $n$ ' for the fore and after body curves is not taking the same. The value of the fore body curve is taken 2 and the value of after the body curve is taken as 1.2. This shape combines the two different forms of hull shape that is the conic and an elliptical shape. The fore body is elliptical and the after body is conical. This makes the body streamlined without causing an increase in the volume or the surface area of the hull of the submarine. The figure below shows the shape of the submarine.

\section{Parallel Mid body Shape Bow}

In this model the value of ' $n$ ' is taken as 3. This increases the degree of the curve to an extent where the mid body becomes parallel. The body is more streamlined at the middle than at the endpoints. The volume of the submarine also increases by a considerable amount making this model more suitable for naval and warfare submarines. The figure below shows the shape of a parallel mid body submarine.

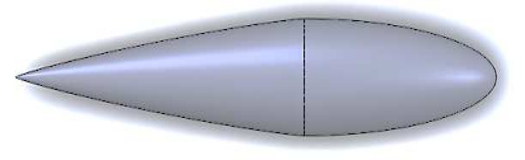

Figure 5: O Give Shape Bow Figure

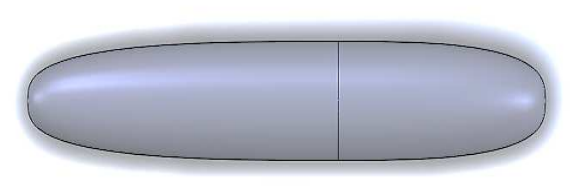

Figure 6: Parallel Mid Body Shape

The models were then imported into Ansys Fluent software. All the models were meshed using Ansys Meshing tools. The tetrahedral mesh command was selected to obtain a sufficiently accurate mesh. The inlet, outlet and wall boundaries of the domain were selected from (Pathan et al., 2017b, c). Meshing completely divides the flow domain into very small elements of defined shape and size. Flow through each element is simulated and then by using the suitable viscous model the total force on the body is found. An inflation layer is also added at the surface boundary of the submarine. Increasing the number of cells at the surface of the submarine increases the accuracy of the results exponentially. The meshed model with flow domain is shown in Fig.8.

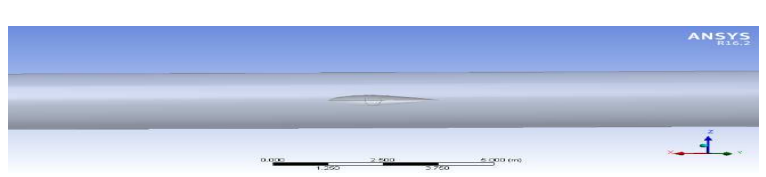

Figure 7: Model within Flow Domain

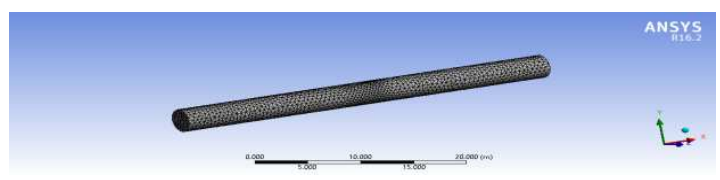

Figure 8: Meshing of Flow Domain 
After giving the velocity input and selecting the standard k- $\varepsilon$ viscous model the simulation software calculated the total resistance by solving the incompressible Reynolds Averaged Navier Stokes equation (RANS). A sufficiently large flow domain was then created for each of the models. The length of the domain in the front and back side of the submarine is considered 5 times of the total length for the analysis. The diameter of the domain is 5 times the maximum diameter of the submarine. All the models have then meshed, and the inlet, outlet and wall boundaries of the domain were assigned. Water is selected as working fluid. As shown in Fig.9, the inlet is defined as a velocity inlet of constant flow. The velocity of the flow can be varied by changing the inlet condition. The outlet is selected as a pressure outlet and the gauge pressure is set to zero.

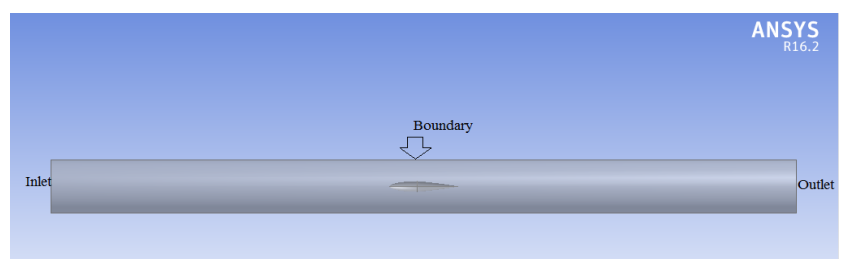

Figure 9: Boundary Conditions

This analysis was carried out for all the models at three different velocities of $3 \mathrm{~m} / \mathrm{s}, 4 \mathrm{~m} / \mathrm{s}$, and $5 \mathrm{~m} / \mathrm{s}$. Several iterations were carried out until the solution is converged. The speeds of $3 \mathrm{~m} / \mathrm{s}, 4 \mathrm{~m} / \mathrm{s}$, and $5 \mathrm{~m} / \mathrm{s}$ are selected because this is the feasible range of speed for a human-powered submarine. For other naval and attack submarines, the range of speed is quite high. As all other parameters are constant the results obtained for the resistance of the models will be purely indicative of the shape and the fineness ratio of the submarine. These results would help us in the selection of the optimum parameters in the design of a human-powered submarine.

\section{RESULTS AND DISCUSSIONS}

The main objective of this paper is to find the optimum fineness ratio at which minimum drag is generated. The contours of pressure, velocity and velocity vectors are plotted using fluent software and displayed in figures Figure10 to 15. These graphs help us understand what the effect of fineness ratio is and flow velocity and hence show how the drag force varies with different models.

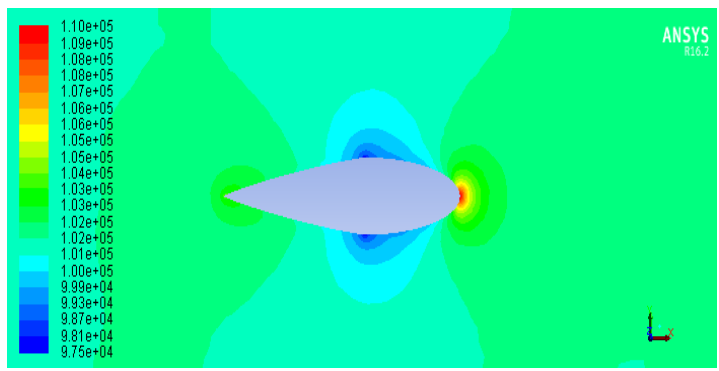

Figure 10: Contours of Pressure for $(\mathrm{L} / \mathrm{D})=4$ at $4 \mathrm{~m} / \mathrm{S}$

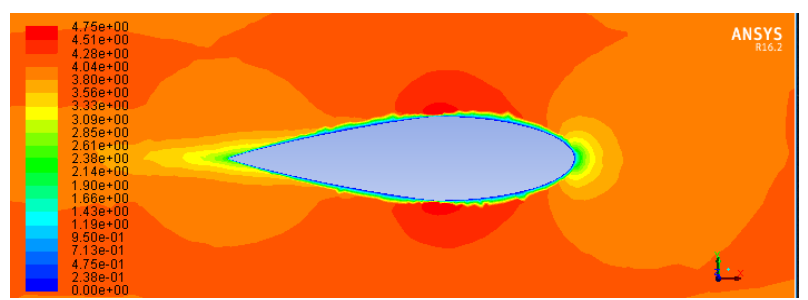

Figure 11: Contours of Velocity for $(\mathrm{L} / \mathrm{D})=4$ at $4 \mathrm{~m} / \mathrm{S}$ 


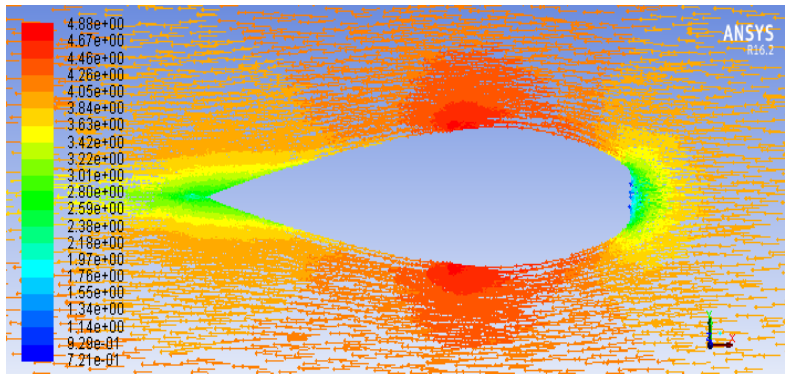

Figure 12: Vectors of Velocity for $(\mathrm{L} / \mathrm{D})=4$ at $4 \mathrm{~m} / \mathrm{S}$

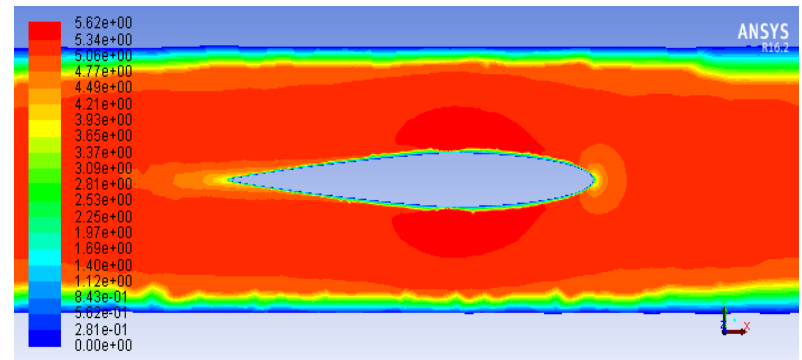

Figure 14: Contours of Velocity for $(\mathrm{L} / \mathrm{D})=8$ at $5 \mathrm{~m} / \mathrm{s}$

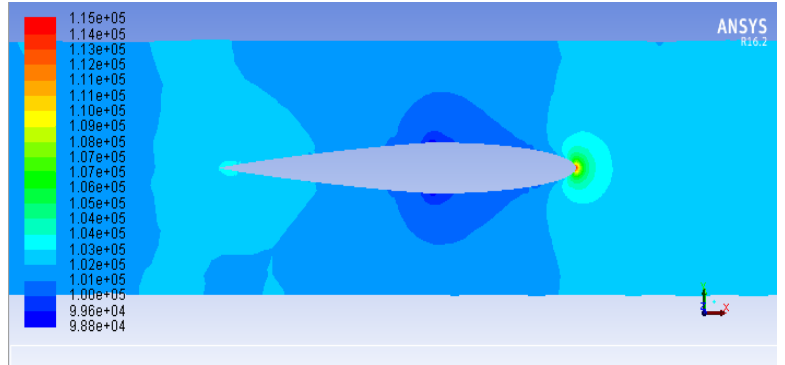

Figure 13: Contours of Pressure for $(\mathrm{L} / \mathrm{D})=8$ at $5 \mathrm{~m} / \mathrm{s}$

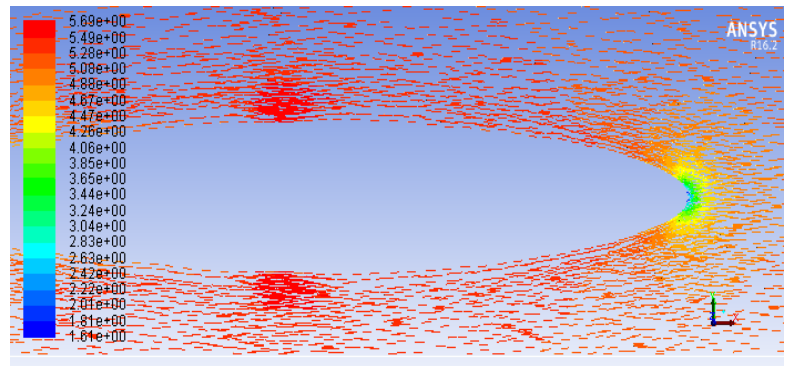

Figure 15: Vectors of Velocity for $(\mathrm{L} / \mathrm{D})=8$ at $5 \mathrm{~m} / \mathrm{S}$

From the above plots, it can be observed that drag is caused due to the development of base pressure and due to the viscous flow at the wall of the submarine. The formation of high pressure on the nose of the submarine and low pressure at the tail gives rise to the back pressure. The viscous flow is due to the skin friction of surface area in contact with the flow. Hence the total drag can be divided into two main components which are viscous drag and pressure drag. The pressure drag depends completely on the shape of the submarine. The more streamlined the shape of the submarine the drag due to pressure will be less. The viscous drag is due to the surface friction of the submarine. It depends on the amount of wetted surface area. As the surface area of the submarine increases the amount of frictional drag also increases. The values of total drag on the bodies for different fineness ratios, at different flow velocities are given in the table below.

From figure 16 to 18 it can be observed that as the fineness ratio increases the drag decreases up to a certain point. After that the drag force starts to increase. This happens because as the fineness ratio increases the body becomes more streamlined and the back-pressure decreases. But at the same time as the fineness ratio increases and the diameter is fixed, the overall surface area increases which in turn increases the surface friction. Hence the fineness ratio at which the total drag on the body is minimum is 6 for Conical shape hull, Elliptical shape hull and Ogive shape hull whereas for the submarine with Parallel mindbody hull shape the optimum fineness ratio is 7.

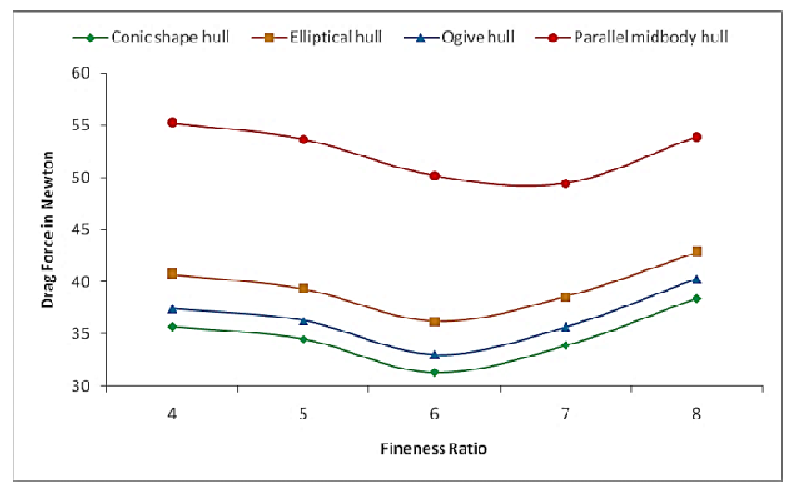

Figure 16: Total Drag at Velocity $3 \mathrm{~m} / \mathrm{s}$ 


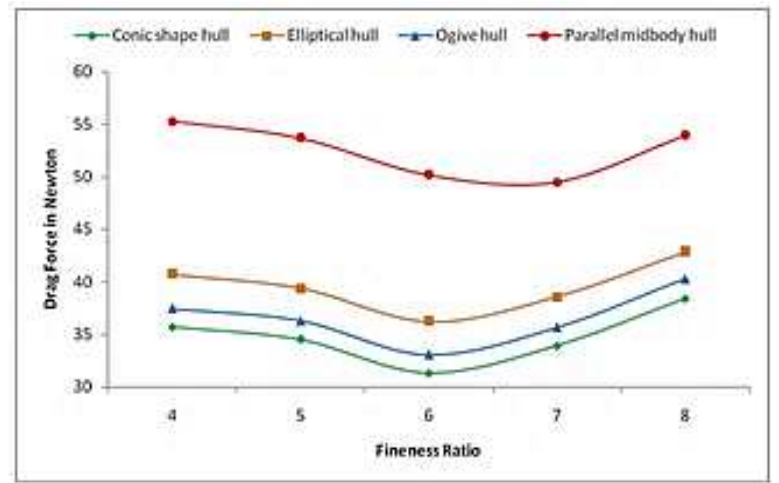

Figure 17: Total Drag at Velocity $4 \mathrm{~m} / \mathrm{s}$

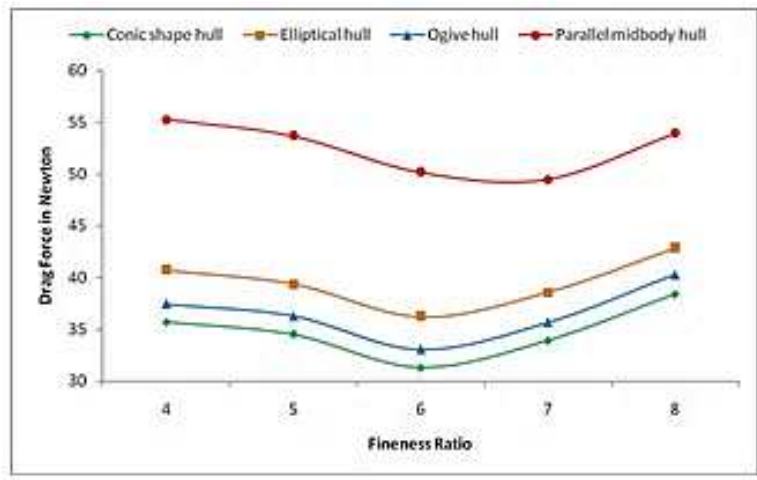

Figure 18: Total Drag at Velocity $5 \mathrm{M} / \mathrm{S}$

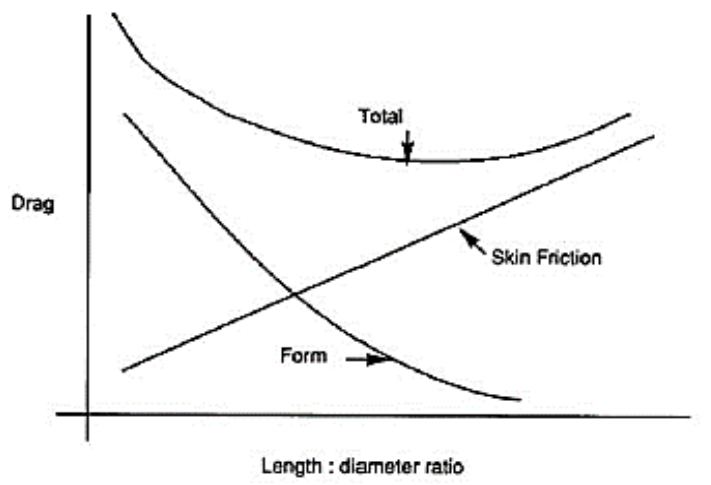

Figure 19: Relation between Drag and Fineness Ratio

It can also observe that the total drag force at all velocities is the minimum for conically shaped hull. This is because conic is the most streamlined shape and has the minimum surface area which reduces the viscous drag. The next shape with minimum total drag is the ogive or teardrop shape. The difference in the total drag of the ogive and conical shape is very less. The optimum fineness ratio of the ogive shape is also found to be 6. This shape has more volume and surface area as compared to the conic-shaped hull. The elliptical hull has a drag greater than both the conical and the ogive-shaped hull. Even though the elliptical hull is smoother the increase in the surface area increases the viscous drag by a significant amount. It also has a greater volume than the other two models.

The parallel mid-body submarine performs the worst with respect to total drag. It has the maximum volume and surface area and hence the maximum amount of viscous drag. Although it has a streamlined body, the large surface area increases the total drag very much. The other parameters that also must be taken into consideration are the surface area and the volume of the different shapes. The surface area affects the total material which will be required for the construction of the submarine and hence will affect the weight of the submarine. The total volume will decide the maximum amount of equipment that can be carried by submarine. The table 2 shows the volume and surface area of each model at the fineness ratio of 6 and figure 19 shows the relationship between drag and fitness ratio.

Table 2: Shape Parameters of Submarine Models at Fineness Ratio 6

\begin{tabular}{|l|c|c|}
\hline Submarine Shape & Volume(mm3) & Surface Area(mm2) \\
\hline Conical & 454664662 & 4165805 \\
\hline Elliptical & 712513639 & 5571647 \\
\hline Ogive & 552690440 & 4694746 \\
\hline Parallel Mid-body & 861745387 & 6314452 \\
\hline
\end{tabular}


From the table the volume of the conie shaped hull is very low. It would be very difficult to fit in the necessary equipment into this limited volume. Also, it would restrict the person to execute proper pedaling motion in the submarine. The amount of oxygen that could be carried along with the person will also reduce decreasing the underwater time of the submarine. Considering all these factors, it would not be recommended to select a conical shape for the submarine even though it gives the best performance. The optimum selection of the shape of the submarine would be the ogive shaped submarine. It has the almost same amount of total drag and enough volume for the submarine. Also, the optimum fineness ratio is found to be 6 for the ogive shaped submarine.

The elliptical and parallel mid-body submarine find a lot use in naval and attack submarines because of their large volume, which could easily fit in a huge amount of people as well as equipment and ammunition. But in our case, it would prove unnecessary to increase the volume of the submarine by such extent in exchange of increase in drag. It can also observe that the total drag increases with an increase in the speed of the submarine. This is because the pressure drops, and the viscous force are both directly proportional to the speed of the submarine. Getting similar results at all different speeds also verifies our results for different fineness ratios.

\section{CONCLUSIONS}

In this paper different types of submarine using curve equations and changing the degree of the equation are modeled. CFD analysis is done on each of the models at 3 different velocities and found the optimum fineness ratio which gives minimum drag force. Total drag includes wave drag, skin friction drags and base drag. At a length of submarine increase the base blunts portion reduces and hence base drag reduces. With increase in length the skin friction drag increase. The optimum value of fineness ratio, which gives minimum drag is 6 for Conical shape hull, Elliptical shape hull and Ogive shape hull whereas for a submarine with Parallel mid-body hull shape the optimum fineness ratio is 7 . This would reduce the amount of effort to be put by the person powering the submarine, increase the top speed that the submarine can achieve and hence increases the chances of winning a race. From the results it can also be concluded that the most effective submarine shape that gives minimum drag is conic shape.

\section{REFERENCES}

1. Prof. P. N. Joubert, "Some aspects of submarine design," University of Melbourne, DSTO 1920.

2. Fluid Mechanics Submarine Design, Australian Maritime College 2011.

3. Mohammed Moonesun et al, "Evaluation of submarine model test in towing tank and comparison with CFD and experimental formulas for fully submerged flows, "Indian Journal of Geo Marine Sciences, 2013.

4. Mohammed Moonesun et al, "CFD analysis of bow shapes of submarines," Journal of Scientific and Engineering Research, 2016.

5. Khizar Ahmed Pathan (2014). "CFD analysis for production of carbon nanotubes," International Journal of Current Engineering and Technology [IJCET], Special Issue3, April 2014, pp 165-169.

6. Reddy, P. R., \& Saikiran, M. Aerodynamic Analysis of Return Channel Vanes in Centrifugal Compressors. International Journal of Mechanical Engineering (IJME), 5(1), 73-82.

7. Pathan Khizar Ahmed, P. S. Dabeer and S. A. Khan (2016). "CFD Analysis of the Supersonic Nozzle Flow with Sudden Expansion," International Organization of Scientific Research-Journal of Mechanical and Civil Engineering (IOSR-JMCE), 
Special Issue Volume 4, pp. 05-07.

8. Cagan, S., \& Buldum, B. Investigation Of The Effect Of Minimum Quantity Lubrication (Mql) On The Machining Of Titanium And Its Alloys A Review.

9. Khizar Ahmed Pathan, P. S. Dabeer and S. A. Khan (2017a), “CFD Analysis of Effect of Area Ratio on Suddenly Expanded Flows," 2nd International Conference on Convergence in Technology (I2CT-2017) Organized by Siddhant College of Engineering, Pune, India and Sponsored by IEEE USA during April 7-9, 2017.

10. Khizar Ahmed Pathan, P. S. Dabeer and S. A. Khan (2017b) "CFD Analysis of Effect of Flow and Geometry Parameters on Thrust Force Created by Flow from Nozzle,” 2nd International Conference on Convergence in Technology (I2CT-2017) Organized by Siddhant College of Engineering, Pune, India and Sponsored by IEEE USA during April 7-9, 2017.

11. Singh, G., \& Singh, J. (2016). Materials to Improve Tensile Strength of Concrete at Micro Level.

12. Khizar Ahmed Pathan, P. S. Dabeer and S. A. Khan (2017c) "CFD Analysis of Effect of Mach number," Area Ratio and Nozzle Pressure Ratio on Velocity for Suddenly Expanded Flows" 2nd International Conference on Convergence in Technology (I2CT-2017) Organized by Siddhant College of Engineering, Pune, India and Sponsored by IEEE USA during April 7-9, 2017. 
